Provided for non-commercial research and education use. Not for reproduction, distribution or commercial use.

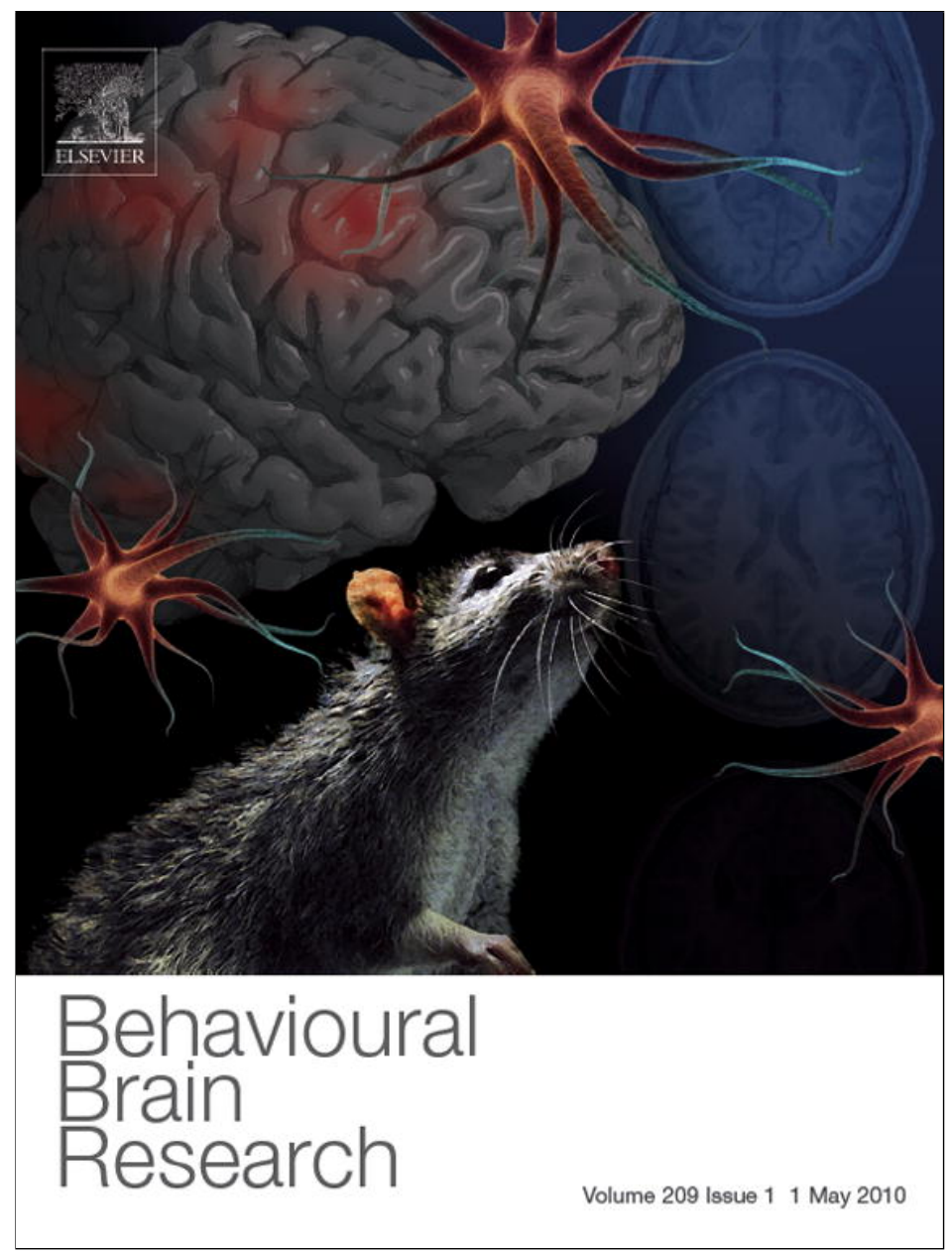

This article appeared in a journal published by Elsevier. The attached copy is furnished to the author for internal non-commercial research and education use, including for instruction at the authors institution and sharing with colleagues.

Other uses, including reproduction and distribution, or selling or licensing copies, or posting to personal, institutional or third party websites are prohibited.

In most cases authors are permitted to post their version of the article (e.g. in Word or Tex form) to their personal website or institutional repository. Authors requiring further information regarding Elsevier's archiving and manuscript policies are encouraged to visit:

http://www.elsevier.com/copyright 
Short communication

\title{
Influence of amygdaloid glutamatergic receptors on sensory and emotional pain-related behavior in the neuropathic rat
}

\author{
Osei B. Ansah ${ }^{\mathrm{a}}$, Nora Bourbia ${ }^{\mathrm{a}}$, Leonor Gonçalves ${ }^{\mathrm{a}, \mathrm{b}, \mathrm{c}}$, Armando Almeida ${ }^{\mathrm{b}}$, Antti Pertovaara ${ }^{\mathrm{a}, *}$ \\ a Institute of Biomedicine/Physiology, University of Helsinki, Helsinki, Finland \\ ${ }^{\mathrm{b}}$ Life and Health Sciences Research Institute (ICVS), School of Health Sciences, University of Minho, Braga, Portugal \\ ${ }^{\mathrm{c}}$ Department of Pharmacology, University College London, London, UK
}

\section{A R T I C L E I N F O}

\section{Article history:}

Received 13 October 2009

Received in revised form 11 January 2010

Accepted 15 January 2010

Available online 25 January 2010

\section{Keywords:}

Amygdala

Aversive place-conditioning

Descending pain modulation

Emotional pain

Mechanical pain sensibility

Peripheral neuropathy

\begin{abstract}
A B S T R A C T
The role of amygdaloid glutamatergic receptors (GluRs) in maintenance of the sensory versus emotional component of neuropathic pain was studied by assessing monofilament-induced limb withdrawal response (sensory pain) and aversive place-conditioning behavior (emotional pain) following amygdaloid administration of various glutamatergic compounds in nerve-injured animals. The results indicate that endogenous activation of amygdaloid group I metabotropic GluRs, $\mathrm{mGluR}_{1}$ and $\mathrm{mGluR}_{5}$, and the NMDA-R contributes to maintenance of sensory and emotional components of neuropathic pain. The predominant effect by amygdaloid group I mGluRs was facilitation of emotional-like pain behavior.
\end{abstract}

(c) 2010 Elsevier B.V. All rights reserved.
The amygdala has an important role in emotions [14] and contributes to processing and modulation of pain [9]. Recent studies indicate that peripheral nerve injury that is associated with chronic pain induces neural plasticity in the amygdala as shown by increased postsynaptic currents evoked by ascending inputs [5] and generation of new amygdala neurons [4]. Additionally, glutamatergic stimulation of the amygdala in nerve-injured animals increases the discharge rate of pronociceptive medullary neurons [1], decreases the discharge rate of antinociceptive pontine neurons [15], and promotes emotional-like pain behavior [1]. These findings support the hypothesis that neural plasticity in the amygdala that involves a change in the function of amygdaloid glutamate receptors plays a role in maintenance of chronic neuropathic pain. However, the contribution of various subtypes of amygdaloid glutamate receptors to the sensory versus emotional (affective-motivational) component of neuropathic pain is still poorly known. In the present study, we investigated the roles of amygdaloid group I metabotropic glutamate receptors (mGluRs) and NMDA-Rs in endogenous regulation of mechanically induced limb withdrawal response (an index for the sensory component of

\footnotetext{
* Corresponding author at: Institute of Biomedicine/Physiology, POB 63, University of Helsinki, 00014 Helsinki, Finland. Tel.: +358 9191 25280; fax: +358919125302.

E-mail address: Antti.Pertovaara@helsinki.fi (A. Pertovaara).
}

pain) and aversive place-conditioning behavior (an index for the emotional component of pain) in animals with a peripheral neuropathy.

The experiments were performed in adult, male HanoverWistar rats weighing $180-190 \mathrm{~g}$ at the beginning of the experiment (Harlan, Horst, The Netherlands). The experimental protocol was accepted by the Institutional Ethics Committee and the experiments were performed according to the guidelines of European Communities Council Directive of 24 November 1986 (86/609/EEC). All efforts were made to minimize animal suffering and to use only the number of animals necessary to produce reliable scientific data.

The unilateral axotomy and ligation of the tibial and common peroneal nerves were performed under pentobarbitone anesthesia (50 mg/kg i.p.) as described in detail earlier [2,3]. After the surgery, the animals were allowed to recover before the actual testing that was performed either 1 or 8 weeks after the operation. Development of hypersensitivity was verified behaviorally in animals habituated to the experimental conditions 1-2 h daily for 2-3 days. Only animals that developed tactile allodynia-like symptoms (the limb withdrawal threshold to monofilament stimulation $\leq 1 \mathrm{~g}$ ) in the sural nerve area of the injured limb were considered further in this study. For control purpose, a group of animals were shamoperated; in the sham group, the operation was identical, except that the nerves were not ligated. Sham operation as well as nerve ligation was performed in the left side. 
The animals were installed with stainless steel guide cannulae (26 gauge; PlasticsOne, Roanoke, VA) for drug administration into the amygdala ipsi- and contralateral to the spared nerve injury under pentobarbitone anesthesia $(50 \mathrm{mg} / \mathrm{kg}$ i.p.) at least one week before behavioral testing. For placement of the guide cannulae, the skull was exposed and holes drilled for their placement. The desired injection sites were in the central nucleus of the amygdala (CeA): $7.12 \mathrm{~mm}$ anterior from the ear bar, $4.00 \mathrm{~mm}$ lateral (left and right) from the midline, and $8.00 \mathrm{~mm}$ ventral from the dura mater [11]. The tips of the guide cannulae were positioned $2 \mathrm{~mm}$ above the desired injection site. The guide cannulae were fixed into the skull using dental screws and dental cement. Dummy cannulae were placed in the guide cannulae, when the animal was not tested.

Drugs or saline control were microinjected into the amygdala through a 33-gauge stainless steel injection cannula (PlasticsOne) inserted through and protruding $2 \mathrm{~mm}$ beyond the tip of the guide cannula. The microinjection was made using a $10 \mu \mathrm{l}$ Hamilton syringe (Hamilton Company, Bonaduz, Switzerland) that was connected to the injection cannula by polyethylene (PE-10) tubing. The volume of injection was $0.5 \mu \mathrm{l}$. At this volume, the spread of the injected drugs within the brain was at least $1 \mathrm{~mm}$ [8]. The efficacy of injection was monitored by watching the movement of a small air bubble through the tubing. The injection lasted $30 \mathrm{~s}$ and the injection cannula was left in place for an additional $30 \mathrm{~s}$ to minimize flow of the drug solution back up the injector track.

Rate of the limb withdrawal response to repetitive monofilament stimulation of the sural nerve area of the injured limb at the force of $1.4 \mathrm{~g}$ (North Coast Medical, Inc., Morgan Hill, CA) was used as an index for the sensory component of pain. The monofilament stimulation was performed five times at about $2 \mathrm{~s}$ intervals. Response rate of $100 \%$ indicates that the animal withdrew the limb at every stimulus presentation, whereas response rate of $0 \%$ indicates that animal did not withdraw its limb at any of the stimulus presentations. Place-avoidance test adapted from that described earlier [6] was used to obtain a measure of emotional pain induced by mechanical stimulation of the injured hind paw. Before testing, the animals were habituated to the test conditions by spending 1-2 h daily for 2 days in the test box. In the actual testing, the rat was placed within a Plexiglas chamber $(60 \mathrm{~cm} \times 30 \mathrm{~cm} \times 30 \mathrm{~cm}$; one half of which was painted black on the external surface) placed upon an elevated metal grid. The rats were placed over the midline of the chamber and stimulation of the plantar surface of the hind paw was performed with a $60 \mathrm{~g}$ monofilament (North Coast Medical, Inc.) once every $15 \mathrm{~s}$ for $15 \mathrm{~min}$. When residing within the dark side of the chamber the injured or sham-operated hind paw was stimulated. Conversely, the non-operated hind paw was stimulated when residing within the light side of the chamber. Throughout the 15 min test period rats were allowed unrestricted movement throughout the chamber. The percent time spent in the light side of the chamber during the 15 min observation period was determined in each condition for each animal. It is assumed that the more aversive the mechanical stimulation of the hind paw, the more the animal spends time in the light side of the chamber; i.e., the place-avoidance test is considered to assess emotional pain behavior [6].

(S)-3,5-dihydroxyphenylglycine (DHPG; an mGluR $_{1 / 5}$ agonist), (RS)-2-chloro-5-hydroxy (CHPG; an $\mathrm{mGluR}_{5}$ agonist), 6-methyl-2-(phenylethynyl)pyridine (MPEP; an $\mathrm{mGluR}_{5}$ antagonist), (+)-MK-801 hydrogen maleate (MK-801; an NMDA-R antagonist) were purchased from Sigma (St. Louis, MO) and 7-hydroxyiminocyclopropan[b]chromen-1a-carboxylic acid ethyl ester (CPCCOEt; an MGluR $_{1}$ antagonist) was purchased from Tocris (Bristol, UK). Physiological saline was used for control injections. Drugs were dissolved in saline, except for CPCCOEt that was dissolved in DMSO. In the choice of drug doses and time points for testing, previously published results $[1,13]$ and preliminary experiments were taken into account.

In the bilateral treatment groups, the drug conditions were saline, DMSO, DHPG at the dose of $10 \mathrm{nmol} / \mathrm{amygdala}$ $(20 \mathrm{nmol} / \mathrm{animal}), \mathrm{MPEP}$ at the dose of $50 \mathrm{nmol} /$ amygdala $(100 \mathrm{nmol} / \mathrm{animal}), \mathrm{MK}-801$ at the dose of $3 \mathrm{nmol} /$ amygdala ( $6 \mathrm{nmol} / \mathrm{animal})$, and CPCCOEt at the dose of $20 \mathrm{nmol}$ or $40 \mathrm{nmol} /$ amygdala ( $40 \mathrm{nmol}$ or $80 \mathrm{nmol} /$ animal), respectively. In the unilateral treatment groups, drug conditions were saline, $20 \mathrm{nmol}$ of CPCCOEt, or $40 \mathrm{nmol}$ of CPCCOEt either ipsi- or contralateral to nerve injury. In all experimental conditions, drugs were administered into the amygdala $5 \mathrm{~min}$ before the start of the place-avoidance test. Duration of the place-avoidance test was $15 \mathrm{~min}$; i.e., place-avoidance test was performed $5-20 \mathrm{~min}$ after amygdaloid administration of the studied compound. Limb withdrawal response to repetitive stimulation of the operated paw was assessed immediately after the end of the place-avoidance test; i.e., limb withdrawal test was performed 20 min after amygdaloid injection of the studied compounds. In each experimental group, each drug condition was assessed in a separate day, 1-2 weeks following nerve injury. Each animal participated in 3-4 drug testing sessions. The interval between different drug conditions in one animal was at least 2 days. The order of testing different drug conditions was varied within the groups to avoid serial effects.

Data are presented as mean \pm S.E.M. One- or two-way ANOVA followed by Tukey's test, $t$-test with a Bonferroni correction for multiple comparisons, or unpaired $t$-test (differences between two experimental groups) were used in statistical analysis of the data. $P<0.05$ was considered to represent a significant difference.

Nerve injury induced marked changes in sensory and emotionallike pain behaviors as indicated by the limb withdrawal response and aversive place-conditioning tests, respectively. In sham-operated control animals $(n=6)$, repetitive monofilament stimulation of the sural nerve area at the force of $1.4 \mathrm{~g}$ produced no responses (not shown), whereas in nerve-injured animals, the limb withdrawal rate following bilateral injection of saline was $92 \pm 5 \%$ ( $n=5$; Fig. $1 \mathrm{~A}$ ). In the aversive place-conditioning test, sham-operated animals spent only $5 \pm 1 \%(n=6)$ of the test time in the light compartment (not shown), whereas saline-treated nerveinjured animals spent $40 \pm 8 \%(n=5)$ of the test time in the light compartment (Fig. 1B). A separate control experiment in nerveinjured animals $(n=5)$ indicated that the limb withdrawal response to repetitive presentation of a monofilament at a force of $1.4 \mathrm{~g}$ was of the same magnitude independent whether the limb withdrawal test was performed before or after the aversive place-avoidance test $\left(t_{8}=0.8, t\right.$-test; not shown). Due to lack of on-going sensory or emotional-like pain behavior in sham-operated animals, painmodulatory influence by endogenous activation of amygdaloid glutamatergic receptors was studied with specific receptor antagonists only in nerve-injured animals.

Bilateral administration of DHPG, an $\mathrm{mGluR}_{1 / 5}$ agonist into the $\mathrm{CeA}(20 \mathrm{nmol} / \mathrm{animal})$, failed to influence limb withdrawal response (Fig. 1A); due to a high baseline value, however, it may not be possible to exclude a DHPG-induced increase in the limb withdrawal response. Bilateral administration of DHPG (20 nmol/animal) increased emotional-like pain behavior (Fig. 1B). Bilateral administration of CPCCOEt, an $\mathrm{mGluR}_{1}$ antagonist, produced a dose-related $(40-80 \mathrm{nmol} / \mathrm{animal})$ decrease in the limb withdrawal response $\left(F_{2,10}=31.2, P<0.0001\right.$; Fig. $\left.1 \mathrm{C}\right)$ and emotional-like pain behavior $\left(F_{2,10}=7.4, P<0.02\right.$; Fig. 1D); at a lower dose (40 nmol/animal), CPCCOEt produced a significant reduction only in the emotional-like pain behavior. Vehicle for CPCCOEt was DMSO. When compared with saline, DMSO alone $(n=4)$ did not influence the limb withdrawal response $\left(t_{7}=0.45\right.$; not shown) or emotional-like pain behavior $\left(t_{7}=0.27\right.$; not shown). Bilateral administration of MPEP, an $\mathrm{mGluR}_{5}$ antagonist, failed to reduce limb withdrawal responses 


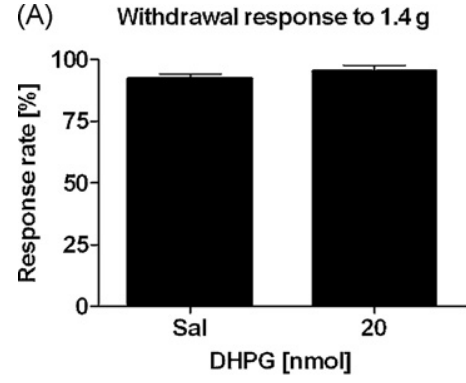

(C) Withdrawal response to $1.4 \mathrm{~g}$

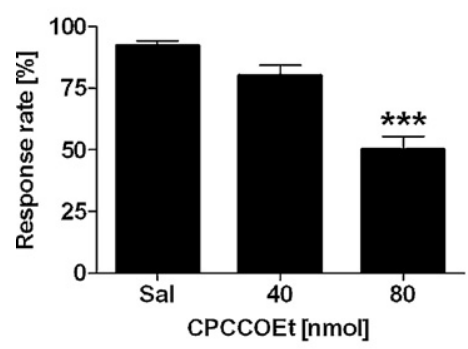

(E) Withdrawal response to $1.4 \mathrm{~g}$

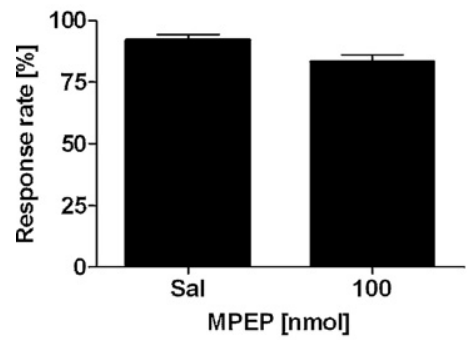

(G) Withdrawal response to $1.4 \mathrm{~g}$

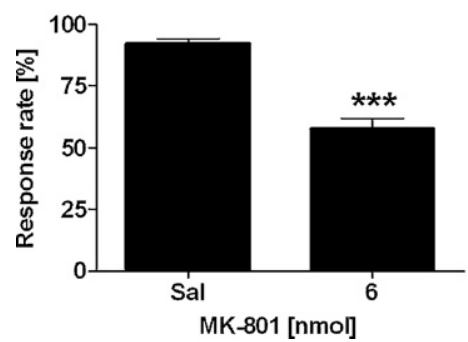

(B) Aversive place-conditioning

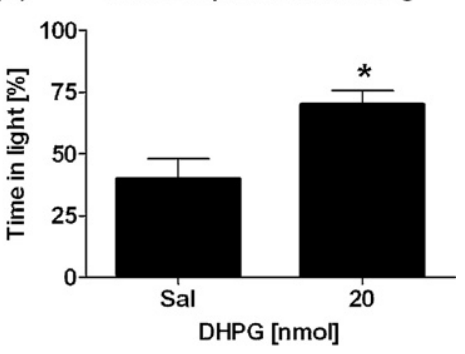

(D) Aversive place-conditioning

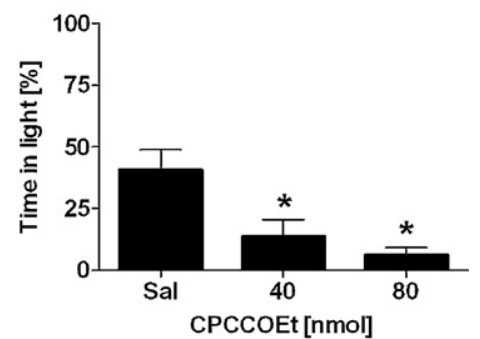

(F) Aversive place-conditioning

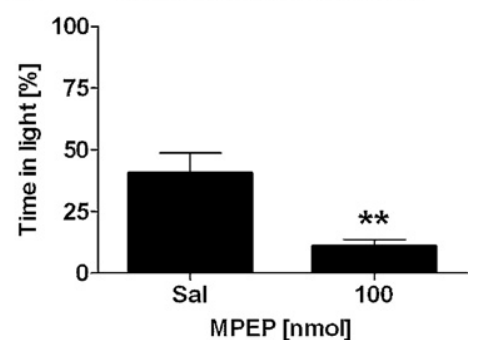

Aversive place-conditioning

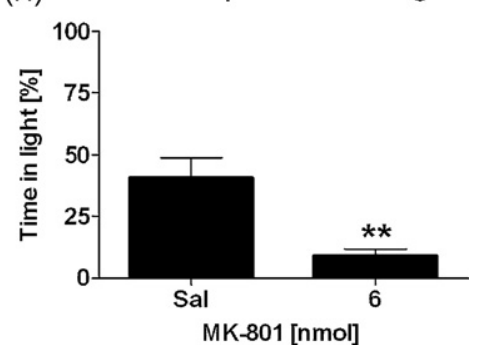

Fig. 1. An index for the sensory component of pain, hind limb withdrawal response elicited by repetitive mechanical stimulation of the nerve-injured paw (left column) and an index for the emotional component of pain, aversive place-conditioning behavior (right column) following bilateral amygdaloid injection of saline (Sal) or various glutamatergic compounds. The doses/animal of the injected glutamatergic compounds are shown in the $X$-axis. A decrease in the limb withdrawal response rate (left columns) and time spent in the light compartment (right columns) are considered to indicate a decrease in sensory and emotional-like pain, respectively. DHPG is an mGluR $\mathrm{B}_{1 / 5}$ agonist, CPCCOEt an mGluR $_{1}$ antagonist, MPEP an MGluR $_{5}$ antagonist, and MK-801 an NMDA-R antagonist. Error bars represent S.E.M. $(n=4-8)$. ${ }^{*} P<0.05$, ${ }^{* *} P<0.01$, ${ }^{* * *} P<0.005$ (in $C$ and D, Tukey's test, in other graphs, $t$-test; reference: the corresponding Sal-group).

at a dose $(100 \mathrm{nmol} / \mathrm{animal}$; Fig. 1E) that was enough to produce a significant attenuation of the emotional-like pain behavior (Fig. 1F). Bilateral administration of MK-801, an NMDA-R antagonist $(6 \mathrm{nmol} /$ animal), produced a significant attenuation of both the limb withdrawal response (Fig. 1G) and the emotional-like pain behavior (Fig. 1H).

CPCCOEt (20-40 nmol/side) or saline was administered unilaterally to study pain-modulatory roles of the CeA ipsi- versus contralateral to nerve injury. Limb withdrawal response was reduced in a dose-related fashion by unilateral injections of CPCCOEt $\left(F_{2,37}=32,7, P<0.0001\right.$; Fig. $\left.2 \mathrm{~A}\right)$. The suppression of the limb withdrawal response was stronger following amygdaloid administration of CPCCOEt contra- than ipsilateral to nerve injury $\left(F_{1,37}=7.55, P<0.01\right)$, independent of the dose $\left(F_{2,37}=2.65\right)$. Unilateral administration of CPCCOEt suppressed also emotional-like pain behavior in a dose-related fashion $\left(F_{2,37}=8.5, P<0.001\right.$; Fig. 2B $)$. Suppression of emotional-like pain behavior was of the same magnitude following unilateral injection of CPCCOEt ipsi- as contralateral to nerve injury $\left(F_{1,37}=0.23\right)$. At the currently used doses, the studied compounds failed to produce any obvious side-effects. Histological analysis indicated that amygdaloid injection sites were in or adjacent to the CeA (Fig. 3).

The present results indicate that amygdaloid group I and NMDA receptors contribute to maintenance of sensory and emotional-like pain in peripheral neuropathy. The finding that group I mGluR antagonists attenuated emotional-like pain behavior at a lower dose than limb withdrawal responses suggests that amygdaloid group I mGluRs may have a more important role in promotion of emotional-like pain than sensory aspects of pain. This finding also suggests that the modulation of emotional-like pain behav- 


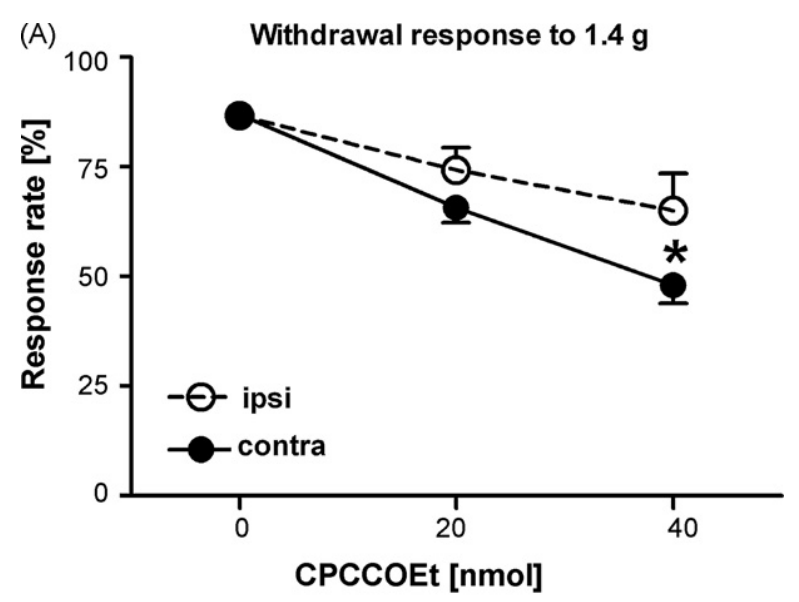

(B) Aversive place-conditioning

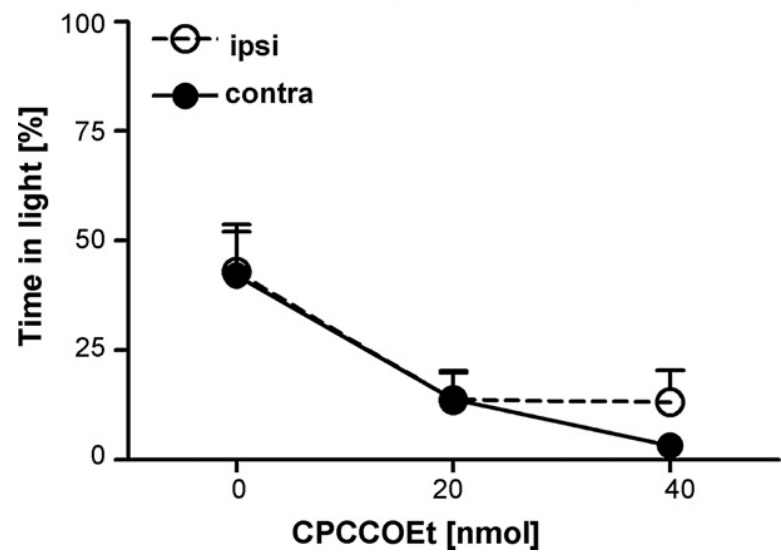

Fig. 2. Hind limb withdrawal response elicited by mechanical stimulation of the nerve-injured paw (A) and aversive place-conditioning behavior (B) following unilateral amygdaloid injection of saline or CPCCOEt (an mGluR $_{1}$ antagonist) at the dose of 20 or $40 \mathrm{nmol} /$ animal. Ipsi = amygdaloid injection ipsilateral to nerve injury, contra = amygdaloid injection contralateral to nerve injury. Error bars represent S.E.M. $(n=4-9) .{ }^{*} P<0.05$ ( $t$-test with a Bonferroni correction; comparison between corresponding values in the ipsi- versus contra-group).

ior by amygdaloid administration of compounds acting on group I mGluRs is predominantly a direct effect on mechanisms underlying emotional pain rather than indirect effect due to enhancement of pain-related sensory signals.

A previous electrophysiological study demonstrated plasticity of synaptic inputs from the parabrachial nucleus to the $\mathrm{CeA}$, and this synaptic plasticity was independent of the NMDA receptor in peripheral neuropathy [5], unlike in inflammatory conditions [7]. In the present study, an NMDA-R antagonist in the CeA facilitated both sensory and emotional-like pain behavior in nerve-injured animals. A possible explanation for these findings is that the amygdaloid NMDA-R plays a role in maintenance of neuropathic symptoms by facilitating inputs from the basolateral amygdala or synaptic signaling between interneurons within the CeA rather than facilitating the ascending spino-parabrachial-amygdala input. It should be noted that nerve injury may induce pathophysiological changes also in the function of various other amygdaloid neurotransmitter receptors, such as $\mathrm{GABA}_{\mathrm{A}}-\mathrm{R}[12$ ] that may contribute to neuropathic symptoms.

Suppression of spinal withdrawal response was slightly stronger following administration of the $\mathrm{mGluR}_{1}$ antagonist into the $\mathrm{CeA}$ contra- than ipsilateral to nerve injury, while the suppression of emotional-like pain was of the same magnitude following ipsi- as contralateral administration. This difference, together with
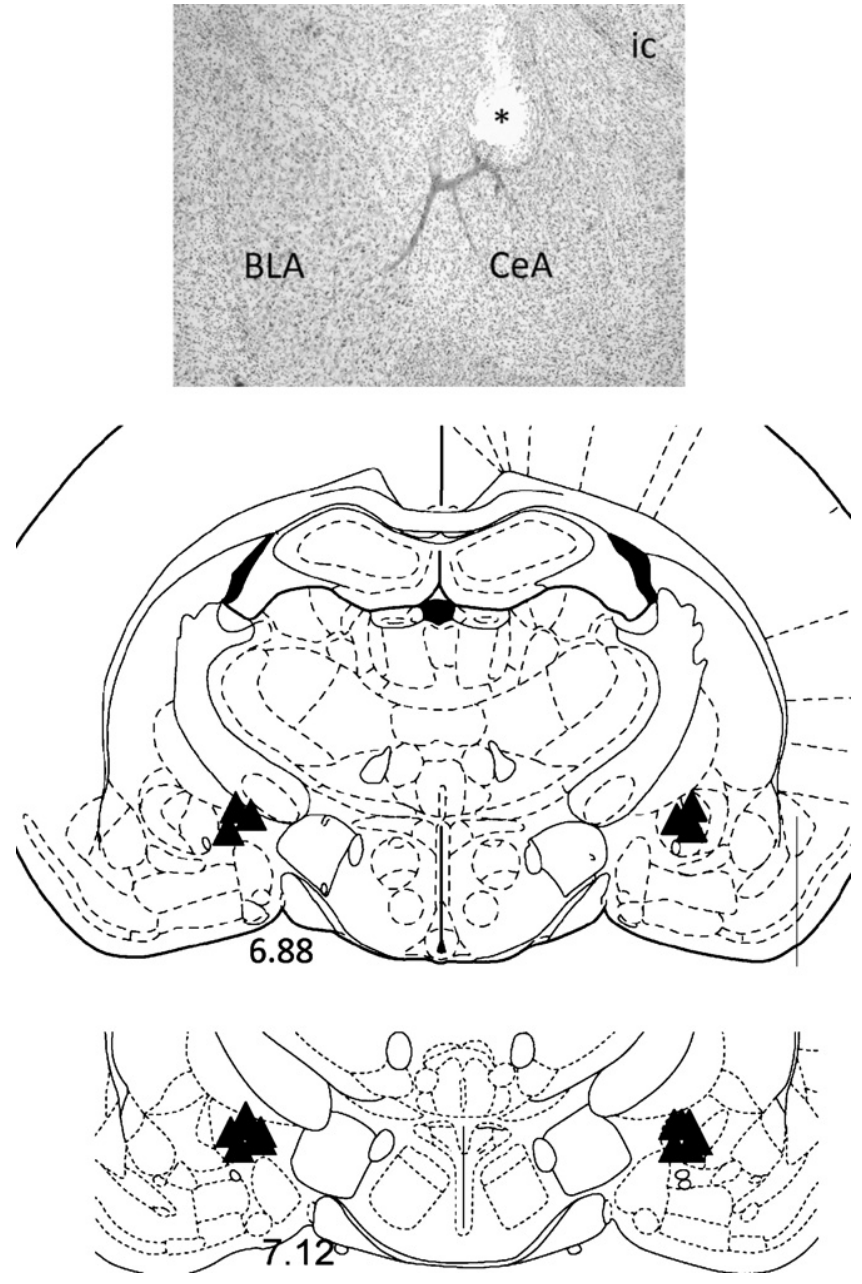

Fig. 3. Injection sites in the amygdala. Upper graph shows an example of a lesion induced by the injection needle in a Nissl-stained coronal section. Triangles in lower schematic diagrams represent injections sites (each triangle represents 1-3 sites). BLA, basolateral amygdaloid nucleus; CeA, central amygdaloid nucleus; ic, internal capsule; and *, tip of the cannula.

the differential dose-dependence in the modulation of sensory and emotional-like pain by group I mGluR antagonists, supports the hypothesis that amygdaloid mechanisms promoting sensory and emotional-like pain in neuropathy are, at least partly, different.

While earlier studies have shown that under physiological conditions the amygdala has a role in induction of analgesia [for review see Ref. [9]], the present results add to the accumulating evidence indicating that under inflammatory $[7,10]$ and neuropathic $[1,5,15]$ conditions amygdaloid glutamatergic receptors may promote pain. Endogenous activation of the amygdaloid group I mGluRs may be of particular importance for the promotion of emotional-like neuropathic pain as revealed by the predominant suppression of the aversive place-conditioning behavior following amygdaloid administration of group I mGluR antagonists in nerve-injured animals.

\section{Acknowledgements}

This study was supported by the Academy of Finland, Helsinki, Finland, the Sigrid Jusélius Foundation, Helsinki, Finland, the Center for International Mobility (CIMO), Helsinki, Finland, the Portuguese Foundation for Science and Technology, Lisbon, Portugal, and the Gulbenkian Foundation, Lisbon, Portugal. 


\section{References}

[1] Ansah OB, Gonçalves L, Almeida A, Pertovaara A. Enhanced pronociception by amygdaloid group I metabotropic glutamate receptors in nerve-injured animals. Exp Neurol 2009;216:66-74.

[2] Decosterd I, Woolf CJ. Spared nerve injury: an animal model of persistent peripheral neuropathic pain. Pain 2000;87:149-58.

[3] Gonçalves L, Almeida A, Pertovaara A. Pronociceptive changes in response properties of rostroventromedial medullary neurons in a rat model of peripheral neuropathy. Eur J Neurosci 2007;26:2188-95.

[4] Gonçalves L, Silva R, Pinto-Ribeiro F, Pêgo JM, Bessa JM, Pertovaara A, et al. Neuropathic pain is associated with depressive behaviour and induces neuroplasticity in the amygdala of the rat. Exp Neurol 2008;213:48-56.

[5] Ikeda R, Takahashi Y, Inoue K, Kato F. NMDA receptor-independent synaptic plasticity in the central amygdala in the rat model of neuropathic pain. Pain 2007; 127:161-72.

[6] LaBuda CJ, Fuchs PN. A behavioral test paradigm to measure the aversive quality of inflammatory and neuropathic pain in rats. Exp Neurol 2000;163:490-4.

[7] Li W, Neugebauer V. Block of NMDA and non-NMDA receptor activation results in reduced background and evoked activity of central amygdala neurons in a model of arthritic pain. Pain 2004;110:112-22.
[8] Myers RD. Injection of solutions into cerebral tissue: relation between volume and diffusion. Physiol Behav 1966;1:171-4

[9] Neugebauer V.Subcortical processing of nociceptive information: basal ganglia and amygdala. In: Cervero F, Jensen TS, editors. Handbook of clinical neurology, vol. 81. Amsterdam: Elsevier; 2006. p. 141-58.

[10] Neugebauer V, Li W, Bird GC, Bhave G, Gereau IV RW. Synaptic plasticity in the amygdala in a model of arthritic pain: differential roles of metabotropic glutamate receptors 1 and 5. J Neurosci 2003;23:52-63.

[11] Paxinos G, Watson C. The rat brain in stereotaxic coordinates. New York: Academic Press; 1998.

[12] Pedersen LH, Scheel-Kruger J, Blackburn-Munro G. Amygdala GABA-A receptor involvement in mediating sensory-discriminative and affective-motivational pain responses in a rat model of peripheral nerve injury. Pain 2007;127: 17-26.

[13] Pertovaara A, Wei H. A dissociative change in the efficacy of supraspinal versus spinal morphine in the neuropathic rat. Pain 2003;101:237-50.

[14] Phelps EA, LeDoux JE. Contributions of the amygdala to emotion processing: from animal models to human behavior. Neuron 2005;48:175-87.

[15] Viisanen H, Pertovaara A. Influence of peripheral nerve injury on response properties of locus coeruleus neurons and coeruleospinal antinociception in the rat. Neuroscience 2007;146:1785-94. 